\title{
X-Ray misses, ct kisses (diagnosis) and stent blows breath of life: tumor in the trachea mimicks exacerbation of COPD
}

\begin{abstract}
An elderly smoker presents in ER with progressive respiratory distress. He is treated as exacerbation of COPD. Atypical behaviour and suboptimal response to treatment prompts further imaging as chest skiagram is not much revealing. CT scan of thorax picks up mass adjoining trachea encroaching the lumen. Bronchoscopy unveils near total occlusion of upper trachea by exophytic growth while Stenting resolves the critical symptoms.
\end{abstract}

Keywords: Central airway obstruction, chronic obstructive pulmonary disease, Tracheal stenting
Volume 4 Issue 3 - 2017

Sushil Upadhyay

Yashoda Superspeciality Hospital, India

Correspondence: Sushil Upadhyay, Yashoda Superspeciality Hospital, HI Kaushambi Ghaziabad, UP, India, Tel: 9899393006 ; Email skupadhyay2007@gmail.com

Received: July 0I, 2017 | Published: July 17, 2017

\section{Introduction}

Chronic obstructive pulmonary disease in exacerbation is the foremost consideration in any elderly individual who presents with breathlessness and history of smoking. More so, if the cardiac cause is ruled out. However, when the response to treatment is suboptimal, other conditions should also be kept in mind. This is warranted when features such as hoarseness are also associated with breathlessness. Chest X-ray is the first line investigation that easily guides to suspect the cause. When chest skiagram appears normal, time to reach the final diagnosis is little delayed. This is what happened in the present case. Further imaging of the chest picked up the cause of new onset wheezy breathlessness at a level higher than expected. It was extension of growth in the trachea compromising the lumen severely.

Clinical manifestations of malignant central airway obstruction (CAO) depend on size, location and the rate of progression of airway obstruction. Moreover, patient's underlying health status and ability to compensate for decreased airflow influences the extent to which symptoms appear. ${ }^{1,2}$ If encroachment into the airway is minor, then there will be little impact on airflow and patients will likely be asymptomatic and never brought to clinical attention. The majority of patients that experience symptoms of CAO have advanced disease and a history of underlying malignancy. ${ }^{3,4}$ Thus, symptoms of CAO are late findings and include dyspnea, cough, wheezing, stridor and frequently, pneumonia. ${ }^{1,3,5}$ Because these symptoms overlap with those found in asthma and COPD, patients with malignant CAO are commonly misdiagnosed. However, a strong indication that symptoms are due to CAO is that they are unresponsive to inhaled steroids and bronchodialators. Other symptoms of advanced CAO are related to signs of decreased ventilation such as tachycardia, diaphoresis and increased work of breathing. ${ }^{3,4}$ It will be helpful to recall the adage "all that wheezes are not asthma (or COPD); all that wheezes is obstruction".

\section{Case report}

Sixty five year old gentleman is brought to emergency department with acute breathlessness. He had been symptomatic for last three months. He complained of persistent non productive cough followed by some hoarseness and lately breathlessness which was progressive in nature. He had been a current smoker with 25 pack years of smoking. He was hypoxemic on room air and was unable to lie flat. He denied symptoms consistent with COPD prior to his present illness lasting for three months. Routine blood chemistry was unremarkable. Echocardiogram showed normal left and right heart functions. Arterial blood gas revealed $\mathrm{pH} ; 7.35, \mathrm{PaCO}_{2}$ of $45 \mathrm{mmHg}$ and $\mathrm{PaO}_{2}$ of $60 \mathrm{mmHg}$ of on 5LPM oxygen through simple mask. Chest diagram Figure 1 showed normal lung fields with normal hila, tracheal and cardiac contours. Injectable antibiotics, steroid, nebulised bronchodilators were started along with oxygen and non invasive ventilation. After two days of treatment he showed signs of improvement and was comfortable most of the times and tolerated removal of BiPAP for few hours. However, he preferred to maintain sitting posture even when in sleep and resisted lying down on the bed. He was noted to have paroxysmal respiratory distress requiring top-up nebulisation and reinstitution of NIV support and these events continued for next few days. Further imaging was planned in view of this unusual behaviour. Contrast enhanced CT scan of thorax was performed. Right paratracheal tumor was noted with extrinsic compression on trachea (Figure 2A-2C). Malignant growth obstructing trachea as the cause of his symptoms was discussed with the family. Bronchoscopy and stenting with involved risks were explained and informed and written consent was obtained. Videobronchoscopy was performed. Left vocal cord was immobile (Figure 3A). Subglottic trachea was circumferentially encroached by fleshy growth reducing the diameter to almost pin-hole size (Figure 3B \& 3C). As bronchoscope was passed beyond the narrowed part the upper and mid tracheal lumen was wide open however encroached on both sides by infiltrating tumor (Figure 3D). Lower third trachea, primary carina and bronchi on both sides were wide and clear (Figure 3E). The dimensions were estimated and $6.0 \mathrm{~cm}$ hybrid Nitinol stent was placed in the trachea covering the tumor extension on both ends (Figure 4). Bronchoscope was withdrawn and patient breathed comfortably even in lying down 
position. Oxygen and BiPAP support were not needed anymore. Nebulization frequency was reduced and also the dose of steroid. Biospy from growth was consistent with moderately differentiated squamous cell carcinoma. He was discharged with advice to follow up with oncology for chemotherapy.

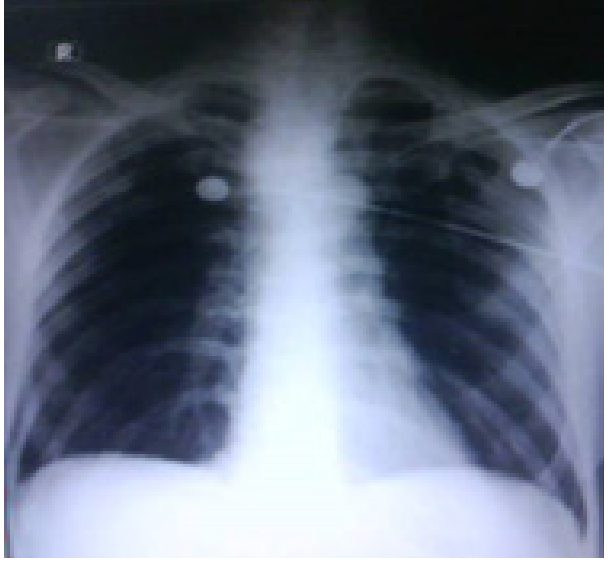

Figure I Chest Xray PA View.

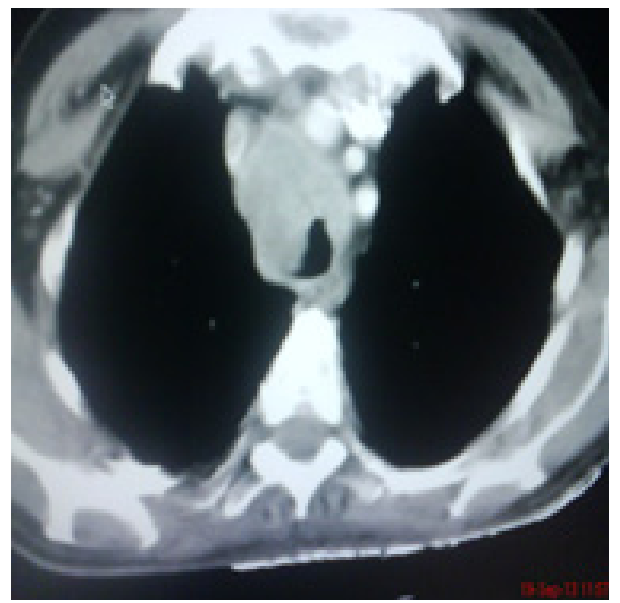

Figure 2A CT Scan: Right Paratracheal Mass.

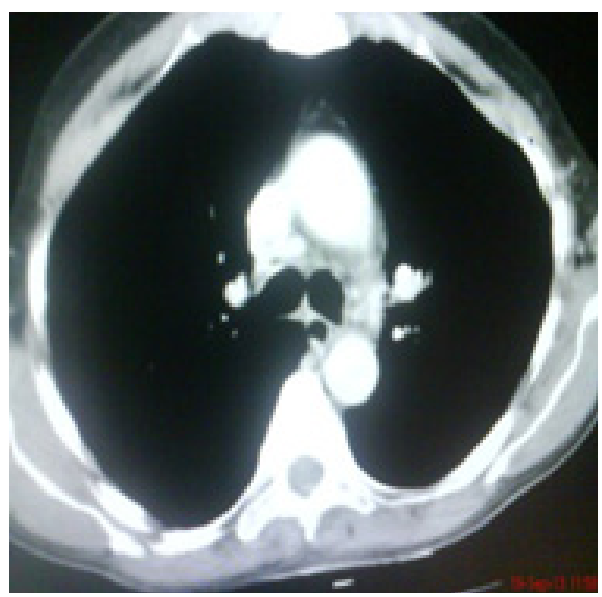

Figure 2B CT Scan at level of carina.

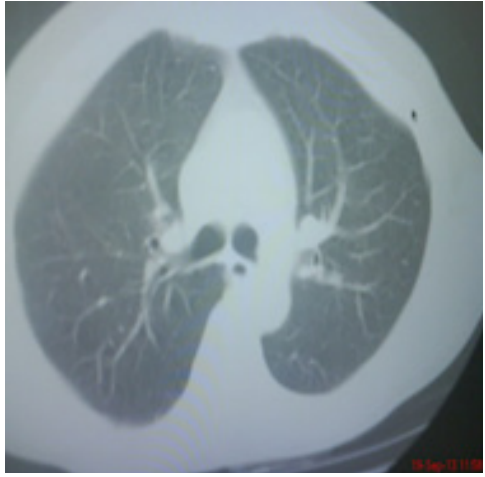

Figure 2C CT Scan at level of carina.

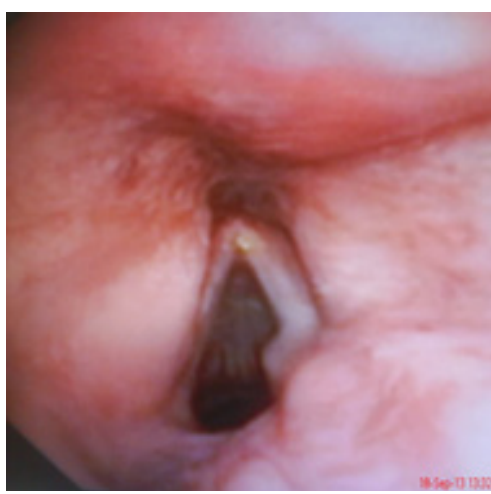

Figure 3A Bronchoscopic view: Left vocal cord palsy.

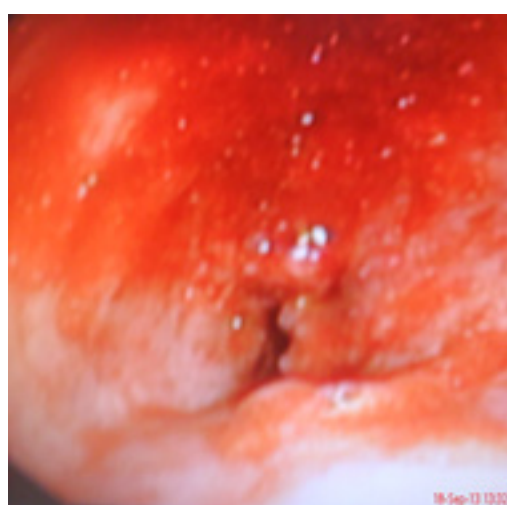

Figure 3B Bronchscopic view subglottic trachea.

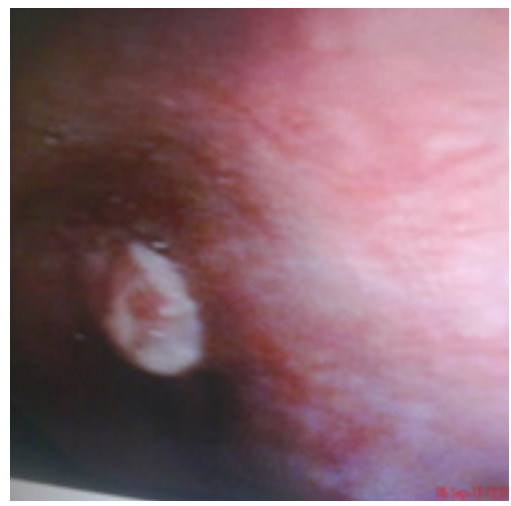

Figure 3C Bronchoscopic view upper trachea. 


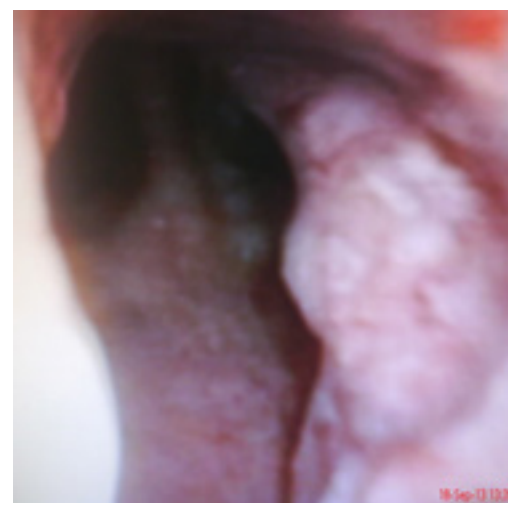

Figure 3D Bronchoscopic view mid trachea.

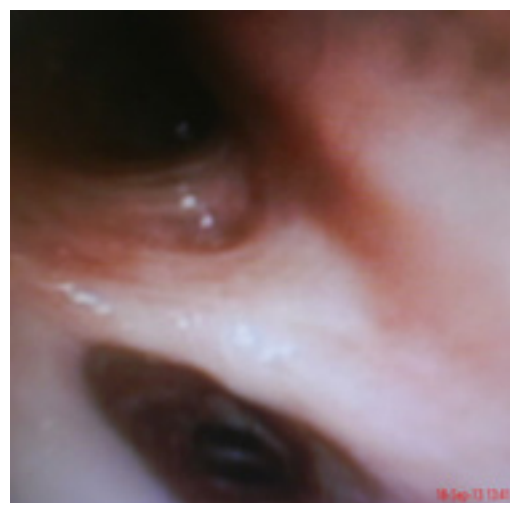

Figure 3E Bronchoscopic view beyond carina.

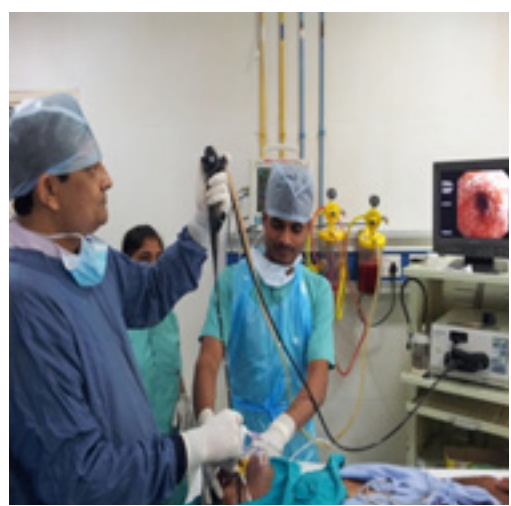

Figure $46.0 \mathrm{~cm}$ Nitinol Stent placed in trachea.

\section{Discussion}

The most common malignant causes of central airway obstructions are direct extension into the airway lumen by extrinsic tumours. Of these tumours the most common types are bronchogenic carcinomas (i. e. small cell lung cancer and non-small cell lung cancer), followed by esophageal and thyroid carcinomas. Primary tumours of the trachea and bronchi, or intrinsic central airway tumours are relatively rare. Seventy to eighty percent of these tumours are of squamous cell or adenoid cystic carcinoma type ${ }^{2}$ Squamous cell carcinomas typically occur later in life and more frequently in men and smokers, while adenoid cystic carcinomas are found in younger patients and are not related to exposure to smoking or to the sex of the patient. ${ }^{5}$
Occasionally, but less frequently, metastases from carcinomas of the breasts, kidneys, colon, thyroid and esophagus may spread to the respiratory system and cause $\mathrm{CAO}^{2,4}$

Evaluation and diagnosis of malignant airways is often based on clinical examinations as well as a tissue biopsy and radiological studies to confirm the diagnosis. While chest radiographs have little diagnostic value, they may be used to quickly rule out other causes of breathing difficulty such as tracheal deviations or a pneumothorax. Chest and neck computed tomography (CT) scans make it possible to estimate tumour size, depth of invasion, and the ability to see if the airway distal to obstruction is still patent, providing important information for treatment planning. CT scans are typically always performed in conjunction with bronchoscopy, the gold standard for evaluating $\mathrm{CAO}^{2}$

The gentleman described here was brought by his sons in the odd hour of night when symptoms were nearly life threatening for the patient. Although he accepted having breathlessness for last few months but it was managed by nebulized bronchodialtors and boluses of steroid as and when needed. Being a regular smoker it was attributed to obstructive lung disease. Even the hoarseness was not presented as chief complaint and was noticed when the patient was able to communicate after partial stabilisation.

Bronchoscopy allows for direct visualization of the tumour, evaluation of tumour length and location, differentiation between an intrinsic endobronchial and extrinsic tumours, and most importantly, is equipped to provide a tissue diagnosis. Moreover, if needed, diagnostic bronchoscopy may be quickly converted to therapeutic bronchoscopy for CAO management. ${ }^{2,5}$ Large airway obstruction due to primary lung cancer or spread from non-bronchial malignancies can produce life threatening and distressing breathlessness, either as an acute presenting symptom of the underlying disease or when recurrence occurs after other treatment. ${ }^{6}$ There are now a number of treatment options available for the relief of distressing breathlessness due to major airway compression from inoperable carcinomas. These include endoscopic surgery, ${ }^{7}$ cryotherapy, ${ }^{8}$ laser photoresection, ${ }^{9}$ and the insertion of silastic ${ }^{10}$ or self expanding metal stents. ${ }^{11}$

Expandable metal stents have been used successfully to relieve airway obstruction.6 Self-expanding metal stents can be inserted under local anaesthesia using the direct vision afforded by a fibreoptic bronchoscope. This could be carried out in any centre where fibreoptic bronchoscopy is available. However, facilities to transfer a patient to a centre offering rigid bronchoscopy should be available in case patients cannot tolerate a fibreoptic bronchoscopy. ${ }^{12}$ Rigid bronchoscopy is also indicated for the removal of stents that have been positioned incorrectly. As reported previously, these stents can be removed up to two weeks after their insertion using rigid bronchoscopy forceps. Thereafter, the stent is covered with tracheobronchial mucosa and, indeed, may not be visible endoscopically after a few months. ${ }^{13}$ In the present case $6.0 \mathrm{~cm}$ nitinol stent was placed in the trachea with the help flexible video bronchoscope which relieved the patient of his symptoms. Patient was gratified so much as if he had got a second breath of life.

\section{Conclusion}

The case reported here emphasizes the need of considering major airway obstruction by tumors in the differential diagnosis in patients who present with symptoms of obstructive airway disease, especially those who do not show satisfactory response to optimized treatment. 


\section{Acknowledgment}

None.

\section{Conflict of interest}

None.

\section{References}

1. Chen K, Varon J, Wenker OC. Malignant airway obstruction: Recognition and management. J Emerg Med. 1998;16(1):83-92.

2. Ernst A, Feller-Kopman D, Becker HD, et al. Central airway obstruction. Am J Respir Crit Care Med. 2004;169(12):1278-1297.

3. Kernstien KH, Reckamp KL. Lung cancer: a multidisciplinary approach to diagnosis and management. Chapter 19, Tracheobraonchial Cancers: Nd: YAG laser resection, brachytherapy, and photodynamic ablation. Demos Medical Publishing, New York, USA, 2011;pp. 235-242.

4. Yeung SCJ, Escalante CP. Holland-Frei oncologic emergencies. Chapter 10, Noninfectious pulmonary emergencies. BC Decker Inc, Hamilton, Canada, 2002;pp. 191-248.

5. Honings J, Gaissert HA, Van Der Heijden H, et al. Clinical aspects and treatment of primary tracheal malignancies. Acta Oto-Laryngologica. 2010;130(7):763-772.
6. Simmonds AK, Irving JD, Clarke SW, et al. Use of expandable metal stents in the treatment of bronchial obstruction. Thorax. 1989;44(8):680-681.

7. Grillo HC. Management of tracheal tumours. Am J Surg 1982;143(6):697-700.

8. Maiwand MO. Cryotherapy for advanced carcinoma of thetrachea and bronchi. BMJ. 1986;293:181-182.

9. Dumon JF, Reboud E, Garbe L, et al. Treatment of tracheobronchial lesions by laser photoresection. Chest. 1982;81(3):278-284.

10. Westaby J, Jackson JW, Pearson FG. A bifuricated silicone rubber stent for relief of tracheobronchial obstruction. J Thorac Cardiovasc Surg. 1982;83(3):414-417.

11. Coolen D, Slabbynck H, Galdermans D, et al. Insertion of a selfexpandable endotracheal metal stent using topical anaesthesia and a fibreoptic bronchoscope: a comfortable way to offer palliation. Thorax. 1994;49(1):87-88.

12. Wilson GE, Walshaw MJ, Hind CR. Treatment of large airway obstruction in lung using expandable metal stents inserted under direct vision via the fibreoptic bronchoscope. Thorax. 1996;51(3):248-252.

13. Donnelly RJ, Hind CR. Expandable metal stents for tracheal obstruction: permanent or temporary? A cautionary tale. Thorax. 1992;47(9):757-758. 